\title{
PENENTUAN TEGANGAN OPERASIONAL PADA DETEKTOR GEIGER MULLER DENGAN PERBEDAAN JARI-JARI WINDOW DETEKTOR
}

\author{
F. Shoufika Hilyana \\ Fakultas Teknik, Program Studi Teknik Elektro \\ Universitas Muria Kudus \\ Email: farah.hilyana@umk.ac.id
}

\begin{abstract}
ABSTRAK
Telah dilakukan penentuan nilai tegangan operasional detektor isian gas Geiger Muller dengan perbedaan jari-jari windownya. Tegangan operasional didapatkan dengan melakukan pencacahan dengan menggunakan tegangan dari 0 Volt sampai 1000 Volt. Detektor Geiger Muller yang digunakan dalam penelitian ini dengan perbedaan jari-jari window $13 \mathrm{~mm} ; 18 \mathrm{~mm}$; dan $20 \mathrm{~mm}$. Hasil penelitian menunjukkan tegangan operasional untuk detektor dengan jari-jari $13 \mathrm{~mm}$ mendapatkan nilai $500 \mathrm{~V}-620 \mathrm{~V}$, detektor dengan jari-jari $18 \mathrm{~mm}$ menghasilkan nilai tegangan $700 \mathrm{~V}-820 \mathrm{~V}$, dan detektor dengan jari-jari $20 \mathrm{~mm}$ mendapatkan nilai tegangan $900 \mathrm{~V}-1000 \mathrm{~V}$. Perbedaan hasil tegangan operasional pada detektor Geiger Muller dikarenakan perbedaan jari-jari windownya. Sehingga dinyatakan bahwa semakin besar jari-jari window detektor Geiger Muller, maka semakin besar pula tegangan operasionalnya. Hal ini dipengaruhi oleh efek ukuran dari detektor, yaitu luas permukaan window detektor Geiger Muller, semakin luas atau besar diameter detektor Geiger Muller, maka semakin banyak pancaran sumber radiasi yang terdeteksi.
\end{abstract}

Kata kunci: tegangan operasional, geiger muller, jari-jari window.

\section{ABSTRACT}

Determining the value of the operating voltages detector gas fields Geiger Muller has been conducted to with different of radius its window. Operating voltages obtained by counting with use from voltage 0 Volt to 1000 Volt. Geiger Muller detector used in this study with different the radius window of $13 \mathrm{~mm} ; 18 \mathrm{~mm}$; and $20 \mathrm{~mm}$. The results showed operating voltage for the detector with a radius of $13 \mathrm{~mm}$ to get the voltage of $500 \mathrm{~V}-620 \mathrm{~V}$, detector with a radius of $18 \mathrm{~mm}$ get the voltage of $700 \mathrm{~V}-820 \mathrm{~V}$, and a detector with a radius of $20 \mathrm{~mm}$ to get the voltage of $900 \mathrm{~V}-1000 \mathrm{~V}$. The operating voltages result is different in Geiger Muller detector due to differences in the radius window. So it is stated that the radius window Geiger Muller detector is larger, the operational voltage is greater. This is influenced by the effect of the detector size, the surface area of the window Geiger Muller detector,if diameter Geiger Muller detector is broader or larger, so the emission sources of radiation detected is more.

Keywords: operational voltage, geiger muller, window radius.

\section{PENDAHULUAN}

Pada tahun 1928 dua asisten Laboratorium Rutherford, Hans Geiger dan W. Muller, menghasilkan teknik yang berbeda untuk mendeteksi partikel. Mereka menemukan sesuatu yang disebut detektor Geiger Muller [1]. Detektor Geiger Muller adalah alat untuk mendeteksi radiasi berdasarkan pasangan ion yang dibentuk di dalam tabung yang berisi gas. Detektor isian gas yang terlihat pada gambar 1, biasanya terdiri dari sebuah tabung berdinding logam yang diisi dengan gas dan mempunyai kawat di tengahnya. Dinding tabung merangkap sebagai katoda sedang kawat sebagai anoda [2].

Pada penelitian Spatz, Operasi pencacahan pada Geiger Muller menyebabkan perubahan karakteristik kurva plateau, setelah digunakan kurva plateau dengan segera sedikit meningkat, dan setelah terus digunakan kurva plateau menjadi tajam. Perubahan pengamatan karakteristik kurva plateau karena dekomposisi dari gas detektor oleh muatan [3]. Dan dalam penelitian Babak, sumber tegangan tinggi dirancang untuk menciptakan tegangan nominal di anoda Geiger-Muller counter di tengah perhitungan tegangan karakteristik (sekitar 400V). Stabilisasi tegangan output dilakukan dengan membatasi amplitudo yang keluar pada sirkuit primer [4].

Detektor isian gas prinsip kerjanya memanfaatkan terjadinya ionisasi gas isian pada medium aktif dalam detektor akibat adanya interaksi dengan zarah radiasi maka akan timbul pasangan ion-elektron. Dengan adanya beda potensial pada anoda dan katoda maka akan timbul medan listrik, sehingga pasangan ion-elektron akan terpisahkan. Ion akan bergerak ke arah katoda dan elektron bergerak ke anoda [5]. 


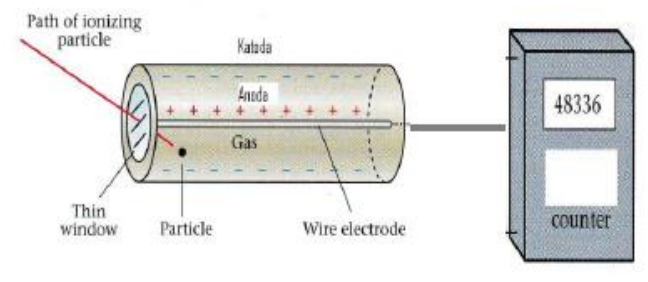

\section{Gambar 2. Skema Detektor Geiger Muller [1]}

Pencacahan yang terbentuk bergantung pada besar tegangan yang dikenakan pada detektor. Ketika tegangan yang terus dinaikkan tidak lagi ada kesebandingan dan tinggi pulsa tidak bergantung pada besar tenaga radiasi yang dideteksi, daerah ini dinamakan daerah Geiger Muller. Daerah Geiger Muller (gambar 2) yang dianggap kurva plateau merupakan rentang tegangan dalam tabung pencacah gas.

Pada daerah I (Rekomendasi), ketika tegangan yang dikenakan masih rendah, elektron dan ion positif yang terbentuk akan segera bergabung kembali. Kalau tegangan terus dinaikkan, maka kemungkinan terjadinya penggabungan kembali elektron dan ion positif dapat diabaikan. Ion-ion yang sampai elektroda akan menghasilkan suatu sinyal pulsa. Daerah ini dinamakan daerah Ionisasi (II). Karena kenaikan tegangan, pada daerah III (daerah Proporsional) elektron yang dibebaskan akan mempunyai tenaga gerak yang cukup besar untuk mengakibatkan ionisasi sekunder, mengionkan atom-atom gas lainnya karena tumbukan. Hal ini menaikkan jumlah muatan yang dikumpulkan pada elektroda dan menaikkan tinggi pulsa yang dihasilkan. Dalam daerah IV, tegangan terus dinaikkan maka tidak ada lagi kesebandingan dan tinggi pulsa tidak lagi bergantung besar tenaga radiasi yang dideteksi. Daerah ini dinamakan daerah Geiger Muller. Di atas daerah Geiger Muller, apabila tegangan terus dinaikkan maka akan terjadi lucutan listrik secara terus menerus dalam tabung gas dan akibatnya detektor menjadi rusak [2].

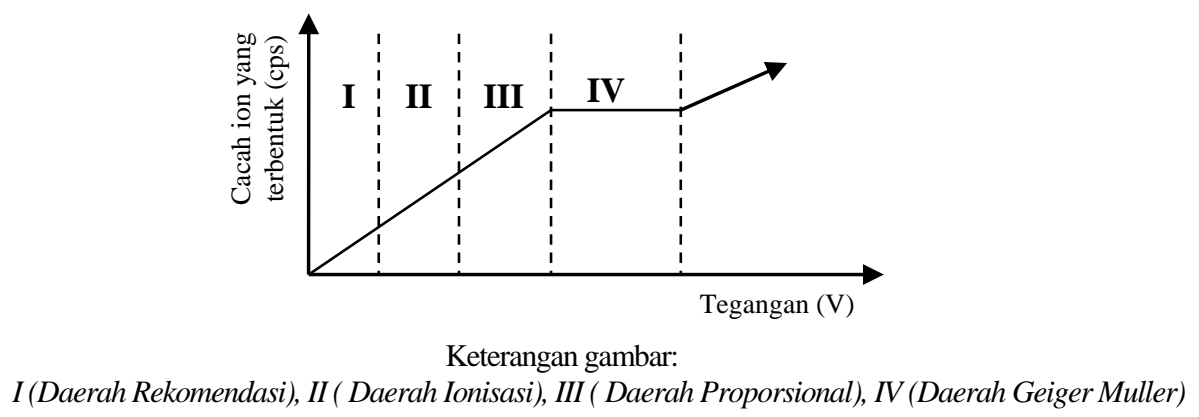

\section{Gambar 3. Kurva Plateau Antara Cacah Ion Terhadap Tegangan Dalam Detektor Isian Gas [6]}

Daerah tegangan operasional detektor Geiger Muller disebut daerah plateau. Pada daerah plateau ini kenaikan tegangan antara anoda dan katoda pada tabung detektor hampir tak mempengaruhi jumlah cacah yang dihasilkan. Panjang daerah plateau detektor Geiger Muller mulai dari tegangan ambang sampai pada batas permulaan tegangan menyebabkan terjadinya lucutan yang terkendali. Pada penelitian Feyves dan Haiman menghasilkan panjang daerah plateau detektor Geiger Muller adalah antara 50 sampai 300 Volt [7].

Daerah Geiger Muller mempunyai dua karakteristik penting, yaitu: banyaknya elektron yang diproduksi tidak dipengaruhi oleh tegangan yang diberikan, dan banyaknya elektron yang diproduksi tidak dipengaruhi oleh banyaknya elektron yang diproduksi oleh radiasi awal. Tegangan diberikan antara anoda dan katoda yang diatur sesuai dengan jenis gas dan aktivitas unsur yang diukur. Tegangan ini harus lebih tinggi daripada nilai ambang, yang didasarkan pada gas dan geometri tabung [8]. Partikel yang dikaji dapat masuk melalui sebuah kaca tipis/jendela mika yang disebut dengan window. Partikel ini lalu menumbuk atom-atom gas sehingga atom-atom gas akan mengeluarkan elektron-elektron. Elektron yang terlepas saat tumbukan ditarik ke anoda. Karena melepaskan elektron, atom-atom gas berubah menjadi ion-ion positif yang kemudian ditarik ke arah katoda.

Pada penelitian ini akan dilakukan penentuan tegangan operasional pada detektor Geiger Muller dengan perbedaan jari-jari window. Penentuan ini diharapkan detektor dapat digunakan secara optimal sesuai dengan tegangan operasionalnya. 


\section{METODOLOGI PENELITIAN}

\subsection{Persiapan Alat}

Penelitian yang dilakukan pada pengambilan data untuk menentukan tegangan operasional dari detektor Geiger Muller menggunakan peralatan eksperimen seperti yang terlihat pada gambar 3. Setelah menyusun alat tersebut, dan mengkalibrasi skalameter pada nilai nol, maka penelitian sudah dapat dilakukan. Detektor Geiger Muller yang digunakan dalam penelitian ini ada tiga jenis dengan perbedaan jari-jari windownya, yaitu dengan jarijari: $13 \mathrm{~mm} ; 18 \mathrm{~mm}$; dan $20 \mathrm{~mm}$. Skalameter yang digunakan dalam penentuan tegangan adalah produksi dari Harris Digicounter England dengan tegangan keluaran dari 240 Volt. Jarak antara detektor dengan sumber yang diberikan adalah $5 \mathrm{~cm}$.

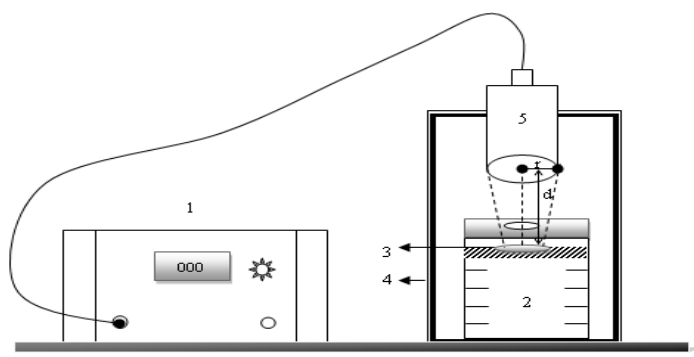

\section{Gambar 4. Susunan Peralatan Eksperimen Untuk Menentukan Tegangan Operasional Pada Detektor Geiger Muller}

Keterangan gambar:

1. Skalameter

2. Plat dengan jarak tertentu

3. Sumber radiasi

4. Papan Pelindung

5. Detektor Geiger Muller, dengan $r=$ jari-jari window; dan $d=$ jarak antara detektor dengan sumber .

\subsection{Proses Pengambilan Data}

Detektor diposisikan pada papan yang sudah diatur jaraknya terhadap tempat sumber atau backgroundnya dan menghubungkan detektor dengan skalameter. Kemudian dilakukan percobaan dengan memvariasi tegangan dari 300 Volt sampai 1000 Volt dengan rentang 20 Volt. Pemberian tegangan pada masing-masing detektor dilakukan pada jarak $5 \mathrm{~cm}$ terhadap background dan sumber radiasi dengan waktu 10 detik sebanyak 5 kali perulangan untuk didapatkan nilai rata-rata. Hasil pencacahan dapat dilihat pada counter yang terdapat pada skalameter. Nilai tegangan operasional Geiger Muller ditentukan pada hasil pencacahan dengan nilai yang hampir sama dan membentuk garis lurus.

\section{HASIL DAN PEMBAHASAN}

Tegangan operasioanl yang digunakan pada detektor Geiger Muller untuk melakukan pencacahan ion yang dibentuk oleh lintasan radiasi yang melalui detektor. Unsur radioaktif akan memancarkan partikel radiasi ke segala arah secara acak. Jadi partikel radiasi yang memancar dari inti belum tentu masuk ke dalam detektor dan belum tentu dapat tercacah oleh detektor. Sehingga dengan interval waktu yang sama (per menit) nilai cacah terkadang naik dan turun, untuk itu perlu adanya pencacahan ulang untuk menghasilkan nilai rata-rata dari cacah per menit. Pada tegangan rendah, detektor tidak akan dapat melakukan pencacahan, tetapi pada tegangan tinggi detektor akan melakukan pencacahan secara kontinu. Ketika detektor diberi sesuai tegangan operasionalnya, maka detektor akan bekerja secara optimal. Sebuah teknik untuk produksi pencacah Geiger Muller terpercaya dijelaskan, dalam penelitian Duffendack [9] dengan tegangan operasonal 400 Volt diproduksi. 
Tabel 1 . Hasil pencacahan Sumber radiasi terhadap Background per 10 detik pada jarak 5 cm pada tiga detektor

\begin{tabular}{|c|c|c|c|c|c|c|c|c|c|c|}
\hline \multirow[b]{2}{*}{ No. } & \multirow[b]{2}{*}{$\begin{array}{c}\text { Tegangan } \\
(\text { Volt })\end{array}$} & \multicolumn{3}{|c|}{ Nilai Cacahan (cpm) Det.1 } & \multicolumn{3}{|c|}{ Nilai Cacahan (cpm) Det.2 } & \multicolumn{3}{|c|}{ Nilai Cacahan (cpm) Det.3 } \\
\hline & & $\begin{array}{c}\text { Back } \\
\text { ground }\end{array}$ & $\begin{array}{c}\text { Sumber } \\
\text { radiasi }\end{array}$ & $\begin{array}{c}\text { Sumber } \\
\text { rad. } \\
\text { thd BG }\end{array}$ & $\begin{array}{l}\text { Back } \\
\text { ground }\end{array}$ & $\begin{array}{c}\text { Sumber } \\
\text { radiasi }\end{array}$ & $\begin{array}{c}\text { Sumber } \\
\text { rad. } \\
\text { thd BG }\end{array}$ & $\begin{array}{c}\text { Back } \\
\text { ground }\end{array}$ & $\begin{array}{c}\text { Sumber } \\
\text { radiasi }\end{array}$ & $\begin{array}{c}\text { Sumber } \\
\text { rad. } \\
\text { thd BG }\end{array}$ \\
\hline 1 & 300 & 0 & 0 & 0 & 0 & 0 & 0 & 0 & 0 & 0 \\
\hline 2 & 320 & 0 & 0 & 0 & 0 & 0 & 0 & 0 & 0 & 0 \\
\hline 3 & 340 & 0 & 0 & 0 & 0 & 0 & 0 & 4,5 & 0 & 0 \\
\hline 4 & 360 & 0 & 0 & 0 & 4,4 & 0 & 0 & 10,4 & 743,2 & 732,8 \\
\hline 5 & 380 & 0 & 0 & 0 & 21,8 & 3,8 & 0 & 11,8 & 753,5 & 741,7 \\
\hline 6 & 400 & 0 & 0 & 0 & 28,6 & 596,4 & 567,8 & 18,6 & 789,2 & 770,6 \\
\hline 7 & 420 & 0 & 0 & 0 & 32,4 & 692,2 & 659,8 & 22,4 & 824,9 & 802,5 \\
\hline 8 & 440 & 10,2 & 217,7 & 207,5 & 33 & 783,2 & 750,2 & 23 & 860,6 & 837,6 \\
\hline 9 & 460 & 12,3 & 221,1 & 208,8 & 38 & 839,2 & 801,2 & 28 & 896,3 & 868,3 \\
\hline 10 & 480 & 12,6 & 233,4 & 220,8 & 39 & 877 & 838 & 29 & 932 & 903 \\
\hline 11 & 500 & 11,9 & 246,3 & 234,4 & 39,6 & 898,4 & 858,8 & 31,2 & 967,7 & 936,5 \\
\hline 12 & 520 & 11,6 & 246 & 234,4 & 38,9 & 916,7 & 877,8 & 35,4 & 1003,4 & 968 \\
\hline 13 & 540 & 11 & 247,3 & 236,3 & 40,8 & 932,9 & 892,1 & 37,6 & 1039,1 & 1001,5 \\
\hline 14 & 560 & 12,3 & 248,7 & 236,4 & 40,4 & 958,7 & 918,3 & 40,4 & 1074,8 & 1034,4 \\
\hline 15 & 580 & 12,7 & 248 & 235,3 & 41,2 & 961,2 & 920 & 41,2 & 1110,5 & 1069,3 \\
\hline 16 & 600 & 11,6 & 249,1 & 237,5 & 47,2 & 1001,1 & 953,9 & 42,4 & 1146,2 & 1103,8 \\
\hline 17 & 620 & 11,6 & 255,2 & 243,6 & 38,9 & 1003,4 & 964,5 & 46,7 & 1181,9 & 1135,2 \\
\hline 18 & 640 & 11 & 267,1 & 256,1 & 40,2 & 1019,7 & 979,5 & 48,3 & 1217,6 & 1169,3 \\
\hline 19 & 660 & 12,3 & 282,9 & 270,6 & 45,1 & 1137,8 & 1092,7 & 51,1 & 1253,3 & 1202,2 \\
\hline 20 & 680 & 11 & 301,7 & 290,7 & 42,2 & 1156,3 & 1114,1 & 52,7 & 1289 & 1236,3 \\
\hline 21 & 700 & 12,3 & 334,2 & 321,9 & 44,3 & 1178,1 & 1133,8 & 59,2 & 1324,7 & 1265,5 \\
\hline 22 & 720 & & & & 39,7 & 1179,6 & 1139,9 & 65,7 & 1360,4 & 1294,7 \\
\hline 23 & 740 & & & & 41,2 & 1179 & 1137,8 & 72,2 & 1396,1 & 1323,9 \\
\hline 24 & 760 & & & & 47,2 & 1176,9 & 1129,7 & 78,7 & 1431,8 & 1353,1 \\
\hline 25 & 780 & & & & 38,9 & 1175,7 & 1136,8 & 85,2 & 1467,5 & 1382,3 \\
\hline 26 & 800 & & & & 39,6 & 1181,2 & 1141,6 & 91,7 & 1503,2 & 1411,5 \\
\hline 27 & 820 & & & & 41,4 & 1174,5 & 1133,1 & 98,2 & 1538,9 & 1440,7 \\
\hline 28 & 840 & & & & 44,8 & 1330,6 & 1285,8 & 104,7 & 1574,6 & 1469,9 \\
\hline 29 & 860 & & & & 42,2 & 1434,3 & 1392,1 & 111,2 & 1610,3 & 1499,1 \\
\hline 30 & 880 & & & & 44,3 & 1538,7 & 1494,4 & 117,7 & 1646 & 1528,3 \\
\hline 31 & 900 & & & & 39,7 & 1542,2 & 1502,5 & 120,3 & 1734,1 & 1613,8 \\
\hline 32 & 920 & & & & & & & 121,7 & 1729,9 & 1608,2 \\
\hline 33 & 940 & & & & & & & 120,6 & 1731,2 & 1610,6 \\
\hline 34 & 960 & & & & & & & 121,2 & 1732,7 & 1611,5 \\
\hline 35 & 980 & & & & & & & 121,5 & 1733,8 & 1612,3 \\
\hline 36 & 1000 & & & & & & & 120,8 & 1732,8 & 1612 \\
\hline
\end{tabular}

Dari hasil penelitian dapat dilihat bahwa pada tegangan yang rendah, belum terjadi pulsa keluaran karena ionion belum mampu ditarik ke anoda/katoda. Bila tegangannya dinaikkan sampai cukup tinggi, artinya dengan kenaikan tegangan akan menurunkan medan magnet yang akan menangkap elektron dari radiasi yang masuk, maka akan diperoleh pulsa keluaran yang dapat dideteksi oleh alat pencacah sebab semua ion dan elektron telah ditarik menuju anoda (elektron) dan menuju katoda (untuk ion positif). Tegangan operasi terpasang pada variasi tertentu akan didapat cacahan bervariasi pula. Untuk menentukan tegangan kerja detektor yang optimal adalah dengan cara mencari perbandingan cacahan sumber terhadap cacahan latar belakang yang terbaik [8].

Bagian kurva tegangan yang hampir datar atau menyerupai garis lurus, jumlah cacahannya disebut plateau atau daerah plateau yaitu daerah yang mendekati nilai konstan dan pada grafik ditunjukkan dengan garis mendatar/hampir datar. Daerah Geiger Muller merupakan daerah dengan tegangan tertentu yang dapat mempercepat elektron primer membentuk elektron sekunder dari ionisasi gas dalam tabung. Tabung Geiger Muller memanfaatkan ionisasi sekunder sehingga setiap tembusan radiasi akan menghasilkan pulsa dan tingginya tetap sama dan tidak dipengaruhi oleh tenaga radiasinya. Oleh karena itu tabung Geiger Muller tidak dapat dipakai untuk mengukur spektrum energi. Bentuk plateau suatu tabung Geiger-Muller merupakan salah satu karakteristik tabung Geiger Muller. Daerah plateau merupakan daerah tegangan operasional detektor. 

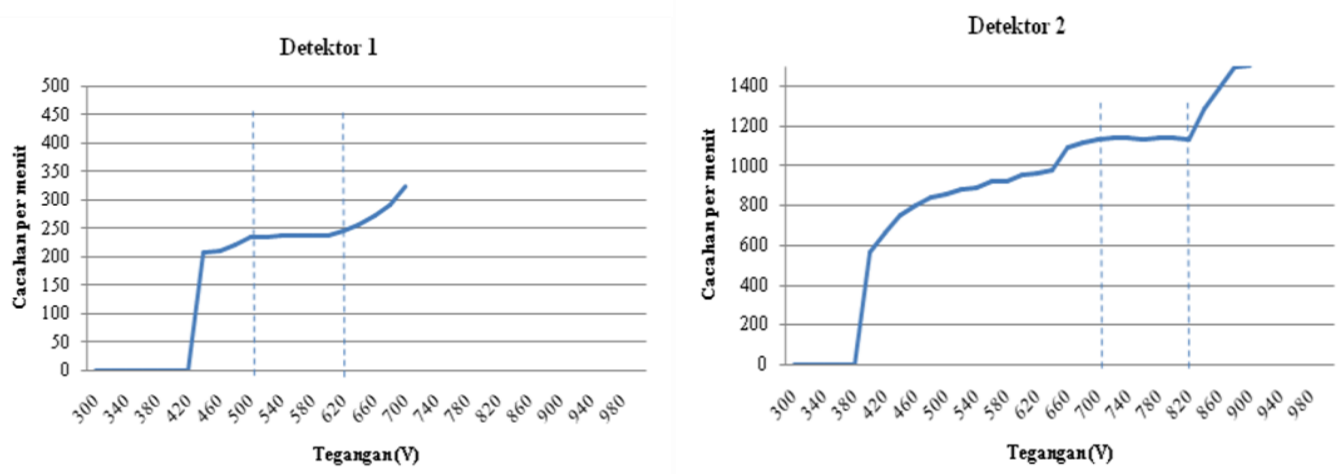

Detektor 3

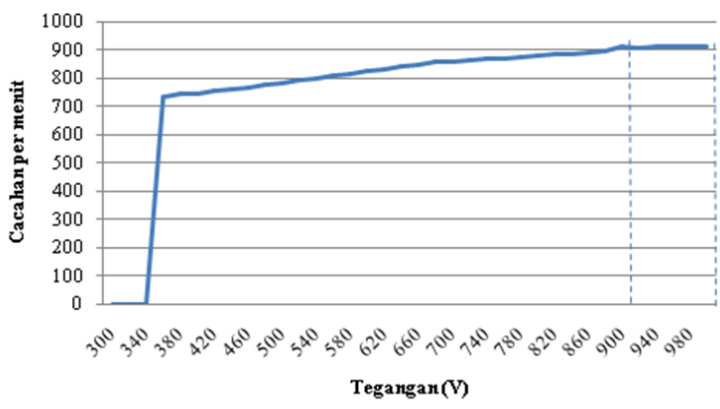

Gambar 5. Hasil Pencacahan dari Ketiga Detektor

Keterangan:

Detektor 1 = Detektor dengan jari-jari $13 \mathrm{~mm}$

Detektor 2 = Detektor dengan jari-jari $18 \mathrm{~mm}$

Detektor 3 = Detektor dengan jari-jari $20 \mathrm{~mm}$

Detektor dengan jari-jari windownya $13 \mathrm{~mm}$ dan $18 \mathrm{~mm}$ sengaja dihentikan pada tegangan 700 Volt dan 900 Volt, karena sudah diketahui tegangan operasional yang didapatkan dan untuk menghindari lucutan listrik secara terus menerus dalam tabung gas dan mencegah detektor menjadi rusak. Tegangan operasional yang dihasilkan oleh ketiga detektor berbeda-beda. Berdasarkan hasil pencacahan dari ketiga detektor (gambar 4) dapat dilihat bahwa, pada detektor 1 dengan jari-jari $13 \mathrm{~mm}$, hasil pencacahan mulai terdeteksi pada saat nilai tegangan $420 \mathrm{~V}$, pada tegangan ini detektor mulai mendeteksi daerah rekomendasi yang seterusnya mengionisasi ketika tegangan $460 \mathrm{~V}-$ $480 \mathrm{~V}$ hingga mencapai daerah proporsional dan mendapatkan hasil tegangan operasional Geiger Muller pada nilai $500 \mathrm{~V}-620 \mathrm{~V}$. Sedangkan pada detektor 2 dengan jari-jari $18 \mathrm{~mm}$, hasil pencacahan mulai terdeteksi pada saat nilai tegangan $380 \mathrm{~V}$, mulai mendeteksi daerah rekomendasi yang seterusnya mengionisasi ketika tegangan $460 \mathrm{~V}$ - $680 \mathrm{~V}$ hingga mencapai daerah proporsional dan mendapatkan hasil tegangan operasional Geiger Muller pada nilai $700 \mathrm{~V}-820 \mathrm{~V}$. Dan untuk detektor 3 dengan jari-jari $20 \mathrm{~mm}$, hasil pencacahan mulai terdeteksi pada saat nilai tegangan $340 \mathrm{~V}$, mulai mendeteksi daerah rekomendasi yang seterusnya mengionisasi ketika tegangan $380 \mathrm{~V}-860$ V hingga mencapai daerah proporsional dan mendapatkan hasil tegangan operasional Geiger Muller pada nilai 900 $\mathrm{V}-1000 \mathrm{~V}$.

Hasil tegangan operasional pada ketiga detektor tersebut berbeda, hal ini dikarenakan terdapat perbedaan pada jari-jari window detektor Geiger Muller. Dari hasil yang didapatkan dapat dinyatakan bahwa semakin besar jari-jari window detektor Geiger Muller, maka semakin besar pula tegangan operasionalnya. Hal ini dipengaruhi oleh efek ukuran dari detektor, yaitu luas permukaan window detektor Geiger Muller, semakin luas atau besar diameter detektor maka semakin banyak pancaran sumber radiasi yang terdeteksi.

\section{KESIMPULAN}

Hasil penelitian dalam menentukan tegangan operasional detektor Geiger Muller dengan perbedaan jari-jari windownya yaitu, tegangan operasional untuk detektor dengan jari-jari $13 \mathrm{~mm}$ mendapatkan nilai $500 \mathrm{~V}-620 \mathrm{~V}$, detektor dengan jari-jari $18 \mathrm{~mm}$ menghasilkan nilai tegangan $700 \mathrm{~V}-820 \mathrm{~V}$, dan detektor dengan jari-jari $20 \mathrm{~mm}$ mendapatkan nilai tegangan $900 \mathrm{~V}-1000 \mathrm{~V}$. perbedaan hasil tegangan operasional pada detektor Geiger Muller dikarenakan perbedaan jari-jari windownya. Sehingga dinyatakan bahwa semakin besar jari-jari window detektor Geiger Muller, maka semakin besar pula tegangan operasionalnya. Hal ini dipengaruhi oleh efek ukuran dari detektor, yaitu luas permukaan window detektor Geiger Muller, semakin luas atau besar diameter detektor Geiger Muller maka semakin banyak pancaran sumber radiasi yang terdeteksi. 


\section{DAFTAR PUSTAKA}

[1] Jones, E., and Childers, R. (1999). Contemporary College Physics. New York: Mc Graw-Hill Companies,Inc.

[2] Susetyo, W. (1988). Spektrometri Gamma dan Penerapannya dalam Analisis Pengaktifan Neutron. Yogyakarta: Gadjah Mada University Press.

[3] Spatz, W. D. B. 1943. "The Factors Influencing the Plateau Characteristics of Self-Quenching Geiger-Mueller Counters." APS Physics Journals Archive 64, 7-8.

[4] Babak, S. 2014. "Radiation Monitoring of Environment Using Unmanned Aerial Complex." The Advanced Science Journal 2014. 12, 41-44.

[5] Sayono, dan Sujitno, B.A.T. (2010). "Pengaruh Tekanan Gas Isian Argon-Etanol dan Argon-Brom Terhadap Unjuk Kerja Detektor Geiger-Mueller”. Jurnal Iptek Nuklir Ganendra, 13. 2, 64-76.

[6] Krane, K. (1982). Fisika Modern. Alih Bahasa Hans J. Wospakrik. Jakarta: UI Press.

[7] Feyves, E. and Haiman, O. (1969). The Phycical Principles of Nuclear Radiation Measurement. Budapest: Academisi Kiado.

[8] Hendro dan Yahya M. N. 2014. Studi Karakteristik Detektor Sodium Iodide Dalam Pemanfaatannya Sebagai Segmented Gamma Scanner Limbah Radioaktif. Jurnal Teknologi Pengelolaan Limbah (Journal of Waste Management Technology) 17. 2, 13-20.

[9] Duffendack, O.S., Lifschutz, H., Slawsky, M.M. 1937. “ Production, Characteristics, and Reliability of Geiger-Müller Counters”. APS Physics Journals Archive 52, 12. 